\title{
An analysis of two indigenous reproductive health illnesses in a Nahua community in Veracruz, Mexico
}

Vania Smith-Oka

\begin{abstract}
Background: This article describes the local concepts indigenous Nahua women hold regarding their reproduction. Specifically it provides a description of two indigenous illnesses-isihuayo and necaxantle, it discusses their etiology, symptoms, and treatments, and it analyzes them within the local ethnomedical framework and sociopolitical context. A perception of female vulnerability is shown to be an underlying shaper of women's experiences of these illnesses.
\end{abstract}

Methods: This research took place in a small Nahua village in Mexico. Qualitative data on local perceptions of these illnesses were collected by a combination of participant observation and interviews. Ethnobotanical data was obtained through interviews, and medicinal plants were collected in home gardens, fields, stream banks, and forested areas. The total study population consisted of traditional birth attendants $(\mathrm{N}=5)$, clinicians $(\mathrm{N}=8)$, and laywomen ( $\mathrm{N}=48)$.

Results: Results showed that $20 \%$ of the village women had suffered from one or both of these illnesses. The article includes a detailed description of the etiology, symptoms, and treatments of these illnesses. Data shows that they were caused by mechanical, physical, and social factors related to a woman's weakness and/or lack of support. Traditional birth attendants often treated women's illnesses. Five medicinal plants were salient in the treatment of these illnesses: Ocimum basilicum L., Mentzelia aspera L., Pedilanthus tithymaloides (L.) Poit., and Piper umbellatum L. were used for isihuayo, while Solanum wendlandii Hook f. was used for necaxantle.

Conclusions: The research on these two ethnomedical conditions is a useful case study to understanding how indigenous women experience reproductive health. Reproductive health is not simply about clinically-based medicine but is also about how biomedicine intersects with the local bodily concepts. By describing and analyzing indigenous women's ill health, one can focus upon the combination of causes - which extend beyond the physical body and into the larger structure that the women exist in.

Keywords: Indigenous ethnomedicine, Women's health, Reproductive health, Medicinal plants, Mexico, Nahua

\section{Background}

The traditional medicine of indigenous groups of Mexico has been very well studied over the past decades [1-7]. Many of these studies show the important role that medicinal plants, local taxonomies, and traditional healers play in people's good health. They also frequently point to the central role of equilibrium-bodily and social-in maintaining people's well-being. Fewer studies, however, analyze the connection between women's

Correspondence: vsmithok@nd.edu

Anthropology Department, 611 Flanner Hall, Notre Dame, IN 46556, USA reproductive health and the broader notions of bodily equilibrium $[5,8,9]$. This article contributes to this discussion by providing an analysis of two reproductive health issues that reflect Nahua indigenous women's concerns with bodily equilibrium and its connection to the local sociopolitical context.

A perception of female vulnerability/weakness (debilidad) exists in many parts of Mexico. This weakness is seen to be due to the physical make-up of a woman's body, caused by the loss of menstrual blood, pregnancy, childbirth, and childcare through breastfeeding. Indigenous perceptions see the reproductive life 
cycle greatly affecting a woman's body, ultimately diminishing her strength or bodily vigor. Such illnesses include organ displacement and those that waste away a woman's body.

Organ displacement is an illness category that is found in both present and past cultures of Mexico [5,10,11], the Americas [12,13], and other regions of the world $[14,15]$. In this illness category, specific organs or parts of the body shift from their original position and cause health problems. The displacement can occur in anyone, from the very young experiencing a fallen fontanelle [16], to women displacing their uterus or pelvic bones [4], to men having displaced testicles, and to both sexes having me'winik, a displacement of an abdominal organ identified by the modern Maya [10]. Organ displacement often causes a loss of equilibrium in the person's body, which must be restored by moving the body part back into its original position.

Isihuayo (pronounced: ee-see-HUA-yoh) is the Nahuatl term to describe the "female part." The term "sihua" denotes femaleness in Nahuatl. The isihuayo is an organ situated in the lower torso of a woman and is believed to have roots radiating out from it. Though isihuayo traditionally described a specific part of the woman's body [17], over the last few years-especially with the contact that the women have increasingly had with biomedicine-this term is now also equated with two other organs in the lower torso: matriz (uterus) and vejiga (bladder). (Both these latter terms are in Spanish). This particular illness is known in other parts of Mesoamerica as caida de matriz, baja de matriz, or caída de vejiga [18]. These terms in Spanish describe the actual displacement of the organ.

Isihuayo is an ethnomedical category of illness with local cultural and biological characteristics, yet it shares many of the latter characteristics with the biomedical condition of prolapsed uterus [19]. The biomedical symptoms for prolapsed uterus include urinary incontinence, discomfort while urinating, constipation, backache, and a lump that projects outside of the vagina [19]. While prolapsed uterus is a condition identified and treated by biomedicine, the isihuayo that the women in the village suffer from differs from prolapse in its etiology and treatment. One of the traditional birth attendants stated that men and women are different because men "do not have ovaries, they have testicles and intestines...[while] we women have the ovaries, the bladder, and the uterus."

Biomedically, prolapsed uterus is caused when the ligaments holding up the uterus weaken and stretch, allowing it to fall down and hang into the vaginal canal. The etiology is multifactorial, including advanced age, obesity, higher parity (number of births), and conditions causing abdominal pressure $[19,20]$. Prolapse was diagnosed when the women attended the clinic to have their annual medical exam and Pap smear. The clinicians at the medical centers stated that surgery was typically the treatment for this condition, where the affected parts of the uterus, or even the entire uterus, were removed. In larger hospitals in cities its treatment could include pelvic floor muscle training, hormones, pessaries, or, in severe cases, surgical treatment [19]. The local physicians did not prescribe pessaries, hormones, or exercises, preferring instead to prevent the condition altogether by advising the women to have fewer children and space them further apart.

Another illness that is connected to women's strength is necaxantle (pronounced: neh-cah-SHAN-tleh). Necaxantle-"the weakening disease"-is a condition that women develop with improper rest after giving birth [21]. It is locally considered a wasting disease. Ideally, women are expected to rest forty days (cuarentena) postpartum so they can regain their bodily strength. Multiple births are believed to increase women's weakness and decrease her body's equilibrium, thus making them more susceptible to various illnesses. Necaxantle shares many elements with the Andean condition of sobreparto. Larme [12] defines sobreparto as "confinement illness," stating that a woman who works in domestic or subsistence activities too soon after giving birth will fall ill. Leatherman [22] adds that because of women's daily realities, most are unlikely to fully adhere to the postpartum regimen of rest and care. Thus women become especially vulnerable to such conditions.

This article aims to describe the local concepts indigenous Nahua women hold regarding their reproduction. Specifically it addresses the following: (1) Provide a description of two indigenous illnesses-isihuayo and necaxantle; (2) Discuss the etiology, symptoms, and treatments of both illnesses; and (3) Analyze these illnesses within the local ethnomedical framework and sociopolitical context.

\section{Study area}

Mexico has slightly over 10 million indigenous people in the country, which is approximately 10 percent of the population. The Nahua are the largest indigenous group, numbering nationally around 1.5 million speakers, mostly found in a wide swath across the central Mexican states from the Gulf coast to the Pacific coast. They are the linguistic descendants of the Aztecs. Overall, indigenous populations form part of the lowest socioeconomic status in the country, with the highest levels of ill health, illiteracy, and marginalization [23].

This ethnographic and ethnobotanical study was conducted over the course of 13 months (between 2004 and 2007) in a Nahua village in the municipality of Ixhuatlán de Madero, in northern Veracruz, Mexico (Figure 1). 


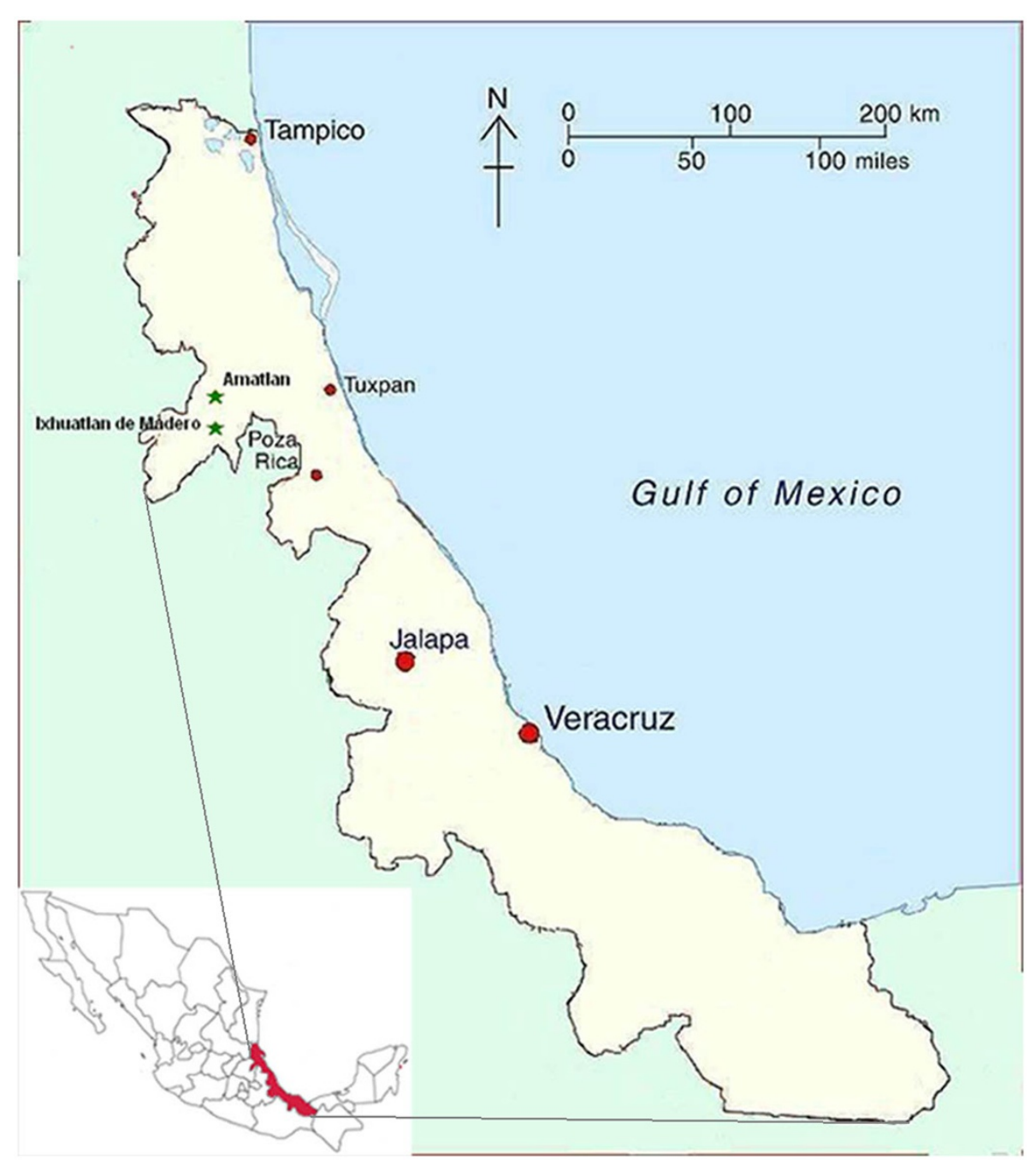

Figure 1 Map of the region of northern Veracruz.

With approximately 600 people, the people of the village are primarily subsistence agriculturalists. Their main crop is maize (Zea mays), complemented by small-scale cattle ranching and orange-farming.

Northern Veracruz is marked by significant ecological and social contrast. The high Sierra Madre Oriental taper eastwards to rolling hills and a lush coastal zone on the Gulf of Mexico. This region of Ixhuatlán lies on the east side of the mountains and receives abundant rain from the warm, moist winds coming over the Gulf of Mexico that drop their water as they cool while rising over the sierras [24]. The rainfall is usually between 2000 and 2500 millimeters per year [3], with the majority of this rain falling in the form of violent thunderstorms in the wet season from July to November. Only about a third of the precipitation falls during the rest of the year, the dry season. The high rainfall during the wet season has given rise to dense tropical forest in the lower areas and temperate oak-ash forest in the highlands $[24,25]$. This has led to a high biodiversity of plants and animals. There are also approximately six hundred species of medicinal plants [26]. Some of the plants that are found in this area include avocado (Persea americana), ceiba (Ceiba pentandra), papaya (Carica papaya), datura (Datura candida), different types of gourds (Crescentia alata), bamboo (Arthrostylidium racemiflorum), mahogany (Swietenia humilis), guava (Psidium guajava), chilies (Capsicum spp.), among many others. Many of these plants are domesticated and, though some of them are found in the remaining forest, the majority have been modified by the people and are grown in their home gardens.

Socially, contrast is evident from the marked differences between wealthy landowners and extremely marginalized indigenous populations. Large industrial cities such as Poza Rica are juxtaposed with the rest of the region, 
which is dotted with small villages and remote hamlets high up in the sierras. Some of the largest cattle ranches in the country, veritable feudal estates [27], are run by a miniscule proportion of the population. The area contains some of the highest rates of illiteracy in the country and a marked lack of services, communications, schools, and jobs. The cities, however, are home to people with a high socioeconomic standard of living [28].

The healthcare in this region consists of biomedicine (government run clinics and hospitals) and traditional healers. The latter include many sobadores (bone setters), curanderos (ritual specialists), and parteras (traditional birth attendants). All the small villages have at least one of these traditional practitioners. In the village where this research takes place, there were nine traditional healers, five of whom were traditional birth attendants (all of them female). All of these women were above the age of 55 and had been practicing most of their adult lives. The parteras have received government training and certification in the nearby city of Poza Rica. Through this certification they have been exposed to some of the biomedical terms for the female body.

\section{Methods}

A mixed methodology of participant observation, indepth ethnographic research (semi-structured and unstructured interviews), and collection of medicinal plants formed the basis of the data. The latter consisted of ex situ interviews that used a combination of fresh material and photographs [29]. The total study population consisted of traditional birth attendants $(\mathrm{N}=5)$, clinicians $(\mathrm{N}=8)$, and laywomen $(\mathrm{N}=48)$. The women ranged in age from 18 to 73, with the average age being 40. The interviews addressed the use of medicinal plants for reproductive purposes, the women's local understandings of the body, their management of plants in their home gardens, and the enrollment of the women in a largescale development program.

As noted by Quinlan [30], participant observation is opportunistic, while also allowing the researcher to engage a large proportion of a population in in-depth conversations. In this research, data has been collected from almost $80 \%$ of the village's women and $100 \%$ of the traditional birth attendants (TBAs). While interviews covered various topics of women's reproductive health, many of them were self-directed by the participants towards a discussion of illnesses locally known as isihuayo and necaxantle. Isihuayo (uterine displacement/prolapse) affected approximately $20 \%$ of the women-though $90 \%$ of the sufferers were above the age of 45 and had 5 or more children. Necaxantle was much less spoken about. Only 2 informants, both over the age of 55, stated they had suffered from it. The illness was well-known and feared across the village, however.
The qualitative data from the interviews was triangulated and cross-checked. These were sorted into piles and groups, and subsequently analyzed. It was analyzed using open and focused coding by identifying and coding trends and patterns [31].

The collection of the medicinal plants was carried out in conjunction with three of the TBAs and Camila, the project's local field assistant. Eight of the laywomen mentioned above were informants regarding plant use. All of them were mothers and were between the ages of 35 and 70, with the average age being 51 . The fact that they were mothers was important, as it meant that they had experience as the primary caretakers of their family's health needs. The TBAs were accompanied during their gathering trips to the pastures, agricultural fields, riverbanks, and disturbed areas; plants were collected from people's home gardens in the village; independent collection was also carried out with the assistance of three key informants. Questions focused particularly on the local uses and taxonomy as well as people's reasoning behind the use of certain plants. It is important to note that home gardens were women's domain and thus a large variety of plants frequently grew there, which women could harvest throughout the year and use for purposes such as food, medicine, ornamental, or construction [32].

During this research, the Spanish and Nahuatl name for as many of the plants as possible was obtained; these were cross-checked for accuracy. Many plants had only one name and were not translated into another language. For most plants, the informants provided a local name as well as their taxonomy. The plants collected were scientifically identified by Mtra. Angélica Ramírez Roa at the National Herbarium of Mexico (MEXU) and the voucher specimens were deposited at MEXU and the Herbario del Instituto de Ecología in Xalapa, Veracruz (IE-XAL).

The research was examined and approved by the Institutional Review Boards of the University of Illinois at Chicago and the University of Notre Dame. The research followed internationally recognized ethical guidelines adopted by the American Anthropological Association. Prior informed verbal consent was obtained from all participants before becoming part of the study.

\section{Results}

\section{Etiology of the illnesses}

The etiology of both illnesses is related to a loss of equilibrium in the woman's body brought about by engaging (or refraining) from certain behavioral norms and expectations.

Isihuayo can be caused by various ways (Figure 2). If a woman falls or is physically hurt, energy is believed to travel into her body, dislodging her uterus. As one woman, Enriqueta, stated, "It fell a lot when I was 


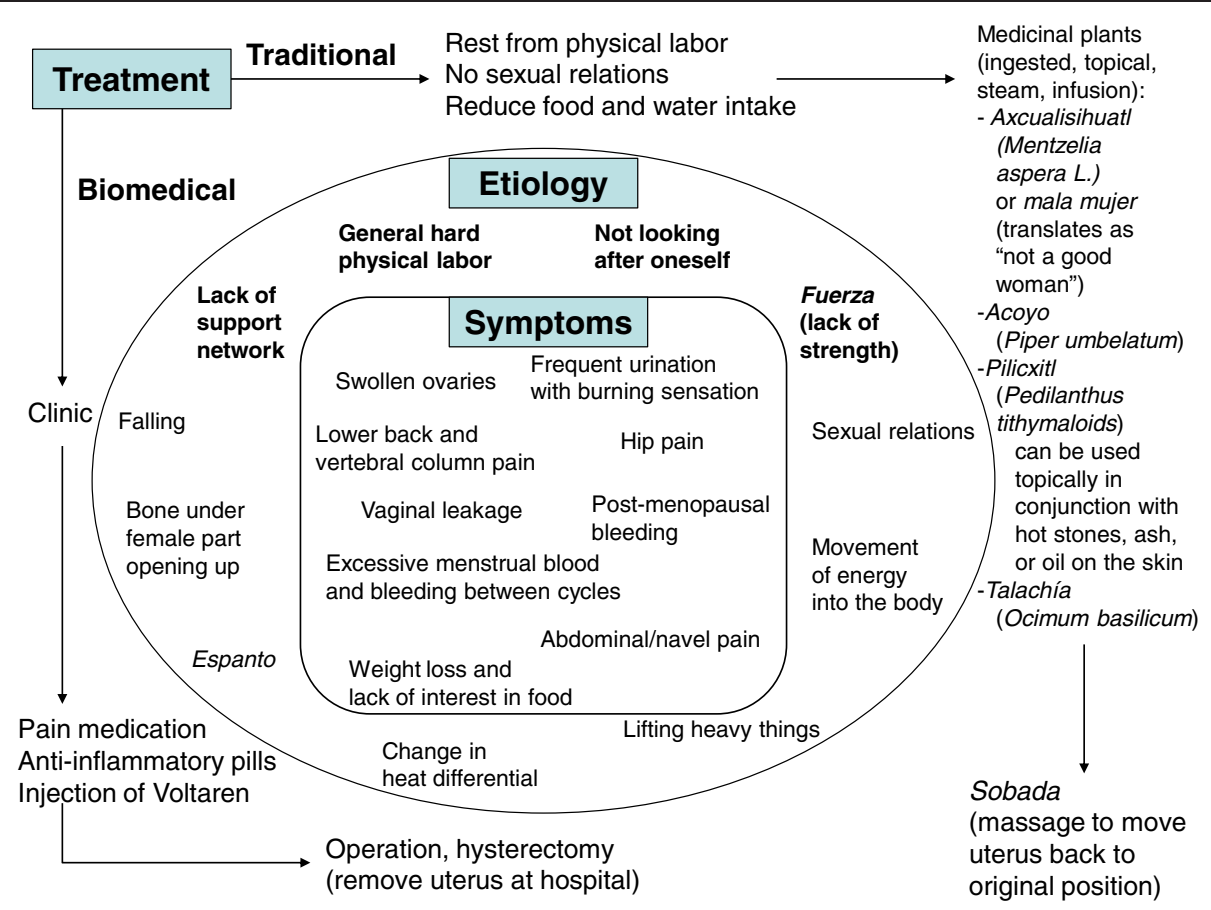

Figure 2 Etiology, symptoms, and treatment for isihuayo.

pregnant with this [second child]. I could feel it when I moved. I came to Lourdes so she could massage me. That's how it was." Carrying heavy loads can affect a woman's female part over time, this especially the case during pregnancy and immediately postpartum. Refugio, a very sought-after TBA, confirmed the etiology of isihuayo. She said about one of her patients, "They say she carries too many buckets and containers of water. And she came to me and said she has pain here [belly] and that is why I massaged her."

A change in heat differential can also cause isihuayo; if, for instance on a hot day a woman is washing clothes in cold water, the internal organs and the body's heat can drastically change, therefore causing the female part to dislodge. Also, excessive sexual relations, in particularly when the woman is tired, can cause the uterus to loosen from its position and hang down. One of the TBAs stated that if a woman in this situation continues with hard physical labor, the uterus will likely remain in this state.

Necaxantle is also caused by imbalance. But this imbalance appears when a postpartum woman does not rest and take care of herself. She does not allow her body to recover. One woman, Esperanza, stated, "[A woman who has just given birth has to rest]. There are some [who rest] for eight days. Others for 15 [days] or a month. But by the next day I was working, as I have no one to help me." Altagracia confirmed this with her own experience of the illness, "I could no longer look after myself. After four days I began to make tortillas. For my first three children [I rested] a week. Afterwards no longer. I began to work in the kitchen. One can get necaxantle [like that]." Among the Mapuche of Chile, for instance, the first few weeks postpartum are considered a period of fragility during which the woman must maintain bodily equilibrium, abstain from sex, and refrain from arduous physical labor [33].

Two important causes of isihuayo and necaxantle are a woman's bodily strength (fuerza) and her source of social support. Lourdes, one of the TBAs, stated, "You see, women are more delicate than men and so any little bump hurts us. [...] It's just that we all have a small bone [underneath the uterus], and if the legs open [wide] after a fall, it will separate and the bladder falls." The uterus is believed to fall through the space and hang down, causing it to become tired and begin to hurt. Jordan [4:43] also noted in her research among the Maya the idea of "bones that [open] during childbirth," which might be a similar etiology to the one experienced by the Nahua women of this region. Lourdes, who, in addition to being a TBA and treating other women's illnesses, also suffered from isihuayo. She said, "I lack fuerza; I lack vitamins. With so much work one gets tired. I need medicine, a treatment." Local perceptions state that a woman's body becomes weaker as she ages as well as through the difficulties encountered in her reproductive life.

Because of the changing nature of indigenous villages across Mexico, which have experienced out-migration and an increased cash flow, family structures are not 
completely stable. Most of the women who have suffered isihuayo and necaxantle have seen their children migrate to cities and border sweatshops, and yet they also become the primary caretakers for their grandchildren. Such a situation leads to a labor-intensive life for these women. They manage all their household domestic duties, oftentimes with little to no help. One of the women stated, "The reason [for isihuayo] is not taking care, we have no one to look after us..." This situation places tremendous strain on their bodies, ultimately causing them to weaken and become ill.

All of the women who suffered from necaxantle and isihuayo expressed their experiences with lack of support. Some of them, such as Juana, were not from the village and so their support came solely from their husband's family. In Juana's case, she had seven children but the older ones migrated to work in the cities, leaving her to care for the younger children. For many years she had no support because her mother-in-law worked as a maid in the city and she had no daughters-in-law to help her. Once her eldest son married and his wife came to live in the village, Juana's health markedly improved. Other women felt the lack of support because they had no daughters to help them. Esperanza's three daughters lived far from the village, though they left some of their children in her care while they worked as maids or in sweatshops on the U.S.-Mexico border. She attributed her health issues to the hard physical labor-carrying heavy containers of water, for instance-to the lack of support from daughters or daughters-in-law. For others, the hard physical life they led, combined with worry about their family, caused their ill-health. Though Lourdes had a daughter-in-law living next door, she experienced a weakening of her body through a combination of a labor-intensive life as a TBA (and thus constantly traveling to surrounding villages to treat patients) and her constant worry about the welfare of her youngest sons. She felt that isihuayo was the underlying cause of her diabetes, which continued to weaken her body, causing even more illness and imbalance.

\section{Symptoms of these illnesses}

Some of the symptoms for isihuayo that were mentioned by the women included excessive menstrual blood, bleeding in between menstrual cycles, post-menopausal bleeding, vaginal discharge, weight loss, and swollen ovaries. Abdominal and navel pain are central symptoms. Because the navel is believed to have roots radiating out of it [17:167), its pain radiates to other parts of the body around it. Women mentioned that they knew they had isihuayo when they experienced pain in the lower back, lower abdomen, hips, vertebral column, and navel. If a woman had any of these symptoms, she usually suspected that she had the illness, though she would not be certain until she had visited a TBA who would diagnose it after palpating and massaging her abdomen.

Because necaxantle's etiology has such a specific timeframe, if a woman felt any discomfort after birth she would know what ailed her (Table 1). Symptoms include generalized body pain and chills, a feeling of weaknesses, lack of hunger, and weight loss. One woman said, "All her body hurts [...] She gets sick, becomes thin. Her body wastes away." Another concurred, adding, "I felt I had no hunger, and my body started to get very thin. My hands were as [thin] as fingers. My [wrists] were like these fingers."

\section{Treatment for these illnesses}

Both necaxantle and isihuayo are treated with any of the following options: behavioral changes, biomedical compounds, care by a traditional birth attendant, care by biomedical clinicians, and/or use of medicinal plants.

Remedies for isihuayo were directed at treating its ultimate cause (the displacement of the organ), rather than solely eliminating the symptoms. As a first step, women were to control the behaviors that caused this condition-abstaining from sexual relations, eating and drinking less (so the uterus was not pressed by the full and heavy bladder, thus being more likely to fall), and reducing physical labor. Figure 2.1 shows some of the active treatments used by the women, particularly those aimed at moving the uterus back to its original position.

Recently-introduced biomedical treatments included pain relief or anti-inflammatory pills and injections to help the uterus settle. Voltaren is a non-steroidal anti-inflammatory drug that works by reducing hormones that cause inflammation and pain in the body. This medical treatment garnered interest in recent years as the TBAs co-opted it for themselves without necessarily knowing

Table 1 Etiology, symptoms, and treatment of necaxantle

\begin{tabular}{ll}
\hline \multicolumn{1}{c}{ Etiology } & \multicolumn{1}{c}{ Symptoms } \\
\hline Lack of care postpartum & Generalized body pain \\
Lacking support network & Weight loss \\
Lack of fuerza & Lack of interest in food $\quad$ No sexual relations \\
Bodily imbalance & Chills \\
& Weakness \\
\hline
\end{tabular}


what the medication was originally intended for. Altagracia, one of the women, commented,

"[Juana] said that she cured herself. That just by taking a plant she got better. [She said] she would drink it like water all day and that she got better. But that plant is far away and none grow near here. It is difficult to go for it. That woman's husband helped her [to get it]. If you look for that plant it sticks to your clothes and you can't get it off. That's probably why it works. She said that just with that she got better, that the [uterus] lifted back [into place]. But the doctor says that nothing will cure it, that neither massages not plants work. [He says] only surgery works."

Regardless of whether the woman used plants or allopathic medication, the uterus had to be manually moved back to its original position by a traditional birth attendant. The TBA would carry out a sobada (traditional massage) on the woman's abdomen and slowly settle the displaced organ back into its place.

Women aimed to prevent necaxantle altogether, though they agreed that this was not always easy to manage because of the increased domestic duties women had. Rest was the immediately prescribed solution. Additionally, a strong belief in the power of vitamins exists throughout Mexico [34]. Vitamin-laden liquids are sold in all pharmacies in the countries and are used for any illness one might have. They are seen to counteract bodily weakness and return strength to the person. Esperanza stated, "They gave me vitamins, only vitamins was I given. And like that it went away."

\section{Medicinal plants used}

Medicinal plants are a central part of the treatment for isihuayo and necaxantle (Table 2). This research project collected 170 plants used in this Nahua community, 80 of which were used medicinally. A total of 26 plants were used to treat issues related to reproduction. Of these plants, 4 were used for isihuayo, while only 1 was used for necaxantle. While most people had a basic knowledge about medicinal plants, the people with the greatest knowledge were women (especially those who were married and had children) and traditional healing specialists.
Plants that are "sticky" or help the uterus "adhere" to its correct position were vital for isihuayo. One such plant is Mentzelia aspera L., which was used in the form of an infusion/tea. This plant was known locally as axcualisihuatl (in Nahuatl) or mala mujer (in Spanish); this translates as "bad woman." The leaves of this plant adhere to skin and clothing with ease; it is this property that was considered to help the uterus adhere to where it belongs.

Another treatment was to squat over a steaming infusion of either acoyo (Piper umbellatum L.) or talachía (Ocimum basilicum L.) so the steam could help a woman's uterus dry up and to settle back into place [21]. Bussman and Glenn [35] note the use of Ocimum basilicum in Peru for reproductive purposes, primarily related to uterine health postpartum.

Refugio, a TBA, stated, "[A woman should put] hot water in a container and [...] steam her parts (raises skirt and pretends to squat over a pretend container), there where the uterus comes out. Because [...] lots of water [comes] out, and [...] it's because the uterus wants to come out. [...] This [treatment] is so that the uterus dries up." Some plants, acoyo (Piper umbellatum L.), or pilicxitl (Pedilanthus tithymaloides (L.) Poit.) were also used topically in conjunction with hot stones, ash, or oil on the skin above the root of the uterus to settle it back into place. Refugio confirmed that these plants helped the uterus to become stronger and harder so it could return to its original position and be able to withstand other problems in the future. The equilibrium in the woman's body was restored through these treatments [21]. Giovannini and Heinrich [7], in their work on medicinal plants among the Mazatec of Mexico, note the use of Piper umbellatum. In this group this plant is used for body pains and nausea rather than for uterine health. They also note the use of Pedilanthus tithymaloides for sore throat and cough.

Only one medicinal plant was used for necaxantle. It is locally called necaxancuamekatl (Solanum wendlandii Hoof. f.)-meaning "plant for necaxantle." A woman who suffered from this illness would bathe with this plant; she would prepare it by crushing it and mixing it with well water. She would bathe with this several times a day until she felt that her symptoms of weakness and lack of hunger disappeared. The woman would

Table 2 Medicinal plants used for treating isihuayo and necaxantle

\begin{tabular}{lll}
\hline Local name & Scientific name & Family \\
\hline Mala mujer & Mentzelia aspera L. & Loasaceae \\
Talachía & Ocimum basilicum L. & Lamiateae \\
Pilicxitl & Pedilanthus tithymaloides (L.) Poit. & Steam \\
Acoyo & Piper umbellatum L. & Topical \\
Necaxancuamekatl & Solanum wendlandii Hook f. & Steam/Topical \\
\hline
\end{tabular}


accompany this treatment with rest so her body could return to normal. Traditional birth attendants also were sought out for this illness. Necaxancuamekatl was not easy to obtain, growing only rarely and in inaccessible places. If a woman needed such a treatment, her relatives would often walk for many miles to another village searching for the plant.

\section{Discussion}

Across Mesoamerica exists the humoral system, consisting of a binary opposition between hot-cold and dry-wet [36]. This constitution does not refer to the actual temperature of a substance but rather refers to characteristics of their temporal nature $[37,38]$. A healthy body is one that has warmth evenly distributed throughout; imbalances may occur, however, due to illness and disturbance of a person's equilibrium by supernatural or natural forces. An imbalance may be of a hot or a cold nature [36] and the medicinal plants chosen to cure the imbalance will be based on the "use of opposites" [1:14]. Hence, a cold plant will be used to cure a hot illness, while a hot one will be used for a cold illness. Many of the treatments for isihuayo or necaxantle used by the Nahua women of this study seem to have a hot temporal quality. The plants are temporally hot and they are also used in conjunction with heating treatments, such as the steam and hot stones. This use is because both isihuayo and necaxantle, by their weakening nature, are cold illnesses. The increase in both humoral and actual temperatures therefore help the women's reproductive body return to equilibrium.

Childbirth complications continue to exact a major toll on women's health worldwide. Most small-scale societies around the world carry out practices to protect women's reproductive health. Among the Kry of Laos, for instance, several steps are taken to protect the woman and newborn infant, such as diets, baths, and use of medicinal plants [39]. The Mapuche of Chile have various postpartum behavioral restrictions for the woman to regain equilibrium [33]. In many of these societies, the role of traditional birth attendants is central to women's health, such as in Guatemala [18], Belize [40], Mozambique [41], or Malaysia [42], to name a few.

Leatherman [22:61], in his analysis of reproductive illnesses in the Andes, proposes an interesting reason for women's poor reproductive health. He states that reproductive illnesses become an accepted reason for reducing one's domestic workload or sexual relations with spouses-they thus allow women to "negotiate some limited control over their productive and reproductive roles." With this view, then, one could conceivable see necaxantle or isihuayo in a different light, perhaps as ways for women to exact some support from relatives or friends in times of need.
In epidemiological terms, these illnesses fall under reproductive morbidity, both obstetric (postpartum issues with necaxantle) and gynecological (prolapsed uterus). Due to issues with cross-cultural definition, underreporting, or the relationship of the women to the larger medical institutions of the nation state there is no worldwide understanding of the way that women from small-scale societies experience these illnesses [43].

\section{Conclusions}

Uterine health concerns occupy a significant portion of the conversations of the Nahua women of this study. Though only a portion had suffered from isihuayo or necaxantle, many women feared these illnesses and spoke about their efforts at prevention. Many of these fears were centered upon the women's workload and feelings of lack of support, which had only increased over the past few decades as the village's structure changed. Over the past few decades, the number of people (especially young women) migrating to the cities has rapidly increased. This situation not only changes the demographics of the village, but also contributes to a shift in older women's responsibilities regarding the domestic sphere.

Though most rural-living Nahua women worked very hard cooking, washing clothes, collecting firewood and water, or tending farm animals, if they lacked additional hands to share the load (in the form of children, siblings, or parents) their work load became heavier and they were more likely to suffer from a bodily imbalance due to exhaustion or weakness. In the case of isihuayo, a woman perhaps had no grown sons to carry heavy loads of water or firewood and no daughters to help with cooking and washing clothes. Thus the overwork led to her weakness and, if one day she happened to fall down, her uterus would likely become dislodged and displaced. The same was true for necaxantle, where if a woman gave birth but had no social support in the form of other women in the household to take on her chores, she had no choice but to begin working soon afterward. Her body thus had no time to recover and so became imbalanced.

The research on these two ethnomedical conditions is a useful case study to understanding how indigenous women experience reproductive health. Reproductive health is not simply about clinically-based medicine (fertility control, prenatal care, or birth options) but is also how this medical system intersects with the local bodily concepts. By describing and analyzing indigenous women's ill health, one can focus upon the combination of causes-which extend beyond the physical body and into the larger structure that the women exist in. Thus, social, economic, and political factors all shape the women's experiences of poor reproductive health. They 
are indigenous women, and thus at the bottom strata of Mexican social/economic hierarchy. They face a changing social structure, brought about by migration, economic welfare programs, and changing medical landscape [9]. And ultimately, their domestic duties and workloads take a toll on their bodies, making them susceptible to ill health.

\section{Author's contributions}

All research herein was designed, conducted, and authored by the author.

\section{Acknowledgments}

This research was funded by grants from the Foundation for the Advancement of Mesoamerican Studies, Inc. (grant \# 05063) and the Institute for Scholarship in the Liberal Arts, College of Arts and Letters, University of Notre Dame. I thank the staff at MEXU for their invaluable help in plant identification, in particular M. en C. Angélica Ramírez Roa. Additional thanks go to Hallie Brewster for image support and to Jessica Bock for help with typing. I am particularly grateful to the many women in the village who, through their knowledge and patience, allowed this work to flourish. I would finally like to thank the anonymous reviewers for their suggestions and careful reading of this article.

Received: 18 June 2012 Accepted: 20 August 2012

Published: 22 August 2012

\section{References}

1. Browner CH: Criteria for selecting herbal remedies. Ethnology 1985 24:13-32.

2. Farfán Morales O: Los nahuas de la sierra norte de Puebla: el chamanismo entre los nahuas. In Estudios nahuas. Edited by Suárez y Farías MC. México: INAH; 1988:127-144.

3. Sandstrom AR: Corn is our Blood: Culture and Ethnic Identity in a Contemporary Aztec Village. Norman: University of Oklahoma Press; 1991.

4. Jordan B: Birth in Four Cultures: A Crosscultural Investigation of Childbirth in Yucatán, Holland, Sweden, and the United States. Prospect Heights, IL: Waveland Press, Inc:; 1993.

5. Castañeda-Camey X, García-Barrios C, Romero-Guerrero X, Nuñez-Urquiza RM, Gonzalez-Hernández D, Glass AL: Traditional birth attendants in Mexico: advantages and inadequacies of care for normal deliveries. Soc Sci Med 1996, 43:199-207.

6. Weimann C, Heinrich M: Indigenous medicinal plants in Mexico: The example of the Nahua (Sierra de Zongolica). Botanica Acta 1997, 110:62-72.

7. Giovannini P, Heinrich M: Xki yoma' (our medicine) and xki tienda (patent medicine)-interface between traditional and modern medicine among the Mazatecs of Oaxaca, Mexico. J Ethnopharmacol 2009, 121:383-399.

8. Groark KP: Vital warmth and well-being: steam bathing as household therapy among the Tzeltal and Tzotzil Maya of highland Chiapas, Mexico. Soc Sci Med 2005, 61:785-795.

9. Smith-Oka V: Unintended consequences: exploring the tensions between development programs and indigenous women in Mexico in the context of reproductive health. So Sci Med 2009, 68:2069-2077.

10. Berlin EA, Jara VM, Berlin B, Breedlove DE, Duncan TO, Laughlin RM: Me'winik: discovery of the biomedical equivalence for a Maya ethnomedical syndrome. Soc Sci Med 1993, 37:671-678.

11. Fuller N, Jordan B: Maya women and the end of the birthing period: postpartum massage-and-binding in Yucatán, Mexico. Med Anth 1981, 5:35-50.

12. Larme AC: Environment, vulnerability, and gender in Andean ethnomedicine. Soc Sci Med 1998, 47:1005-1015.

13. Singer M, Davison L, Gerdes G: Culture, critical theory, and reproductive illness behavior in Haiti. Medical Anthropology Quarterly 1988, 2:370-385.

14. Meyer CL: The Wandering Uterus: Politics of Reproductive Rights of Women. New York: New York University Press; 1997.

15. Earth B, Sthapit S: Uterine prolapse in rural Nepal: gender and human rights implications. Culture, Health \& Sexuality 2002, 4:281-296.
16. Hinojosa SZ: The Mexican American sobador, convergent disease discourse, and pain validation in south Texas. Hum Org 2008, 67:194-206.

17. López Austin A: The Human Body and Ideology. In Concepts of the Ancient Nahuas, Vol. I. Edited by Ortiz de Montellano T, Ortiz de Montellano B. Salt Lake City: University of Utah Press; 1988.

18. Cosminsky S: Maya midwives in southern Mexico and Guatemala. In Mesoamerican Healers. Edited by Huber BR, Sandstrom AR. Austin: University of Texas Press; 2001:179-210.

19. Doshani A, Teo REC, Mayne CJ, Tincello DG: Uterine prolapse. B Med J 2007, 335:819-823.

20. Mant J, Painter R, Vessey M: Epidemiology of genital prolapse: observations from the Oxford family planning association study. B J Obs Gyn 1997, 104:579-585.

21. Smith-Oka V: Plants used for reproductive health by Nahua women in northern Veracruz, Mexico. J Econ Bot 2008, 62:604-614.

22. Leatherman T: A space of vulnerability in poverty and health: political-ecology and biocultural analysis. Ethos 2005, 33:46-70.

23. Comisión Nacional Para el Desarrollo de los Pueblos Indígenas: Indicadores y estadísticas. Mexico City: CDI; http://www.cdi.gob.mx/index.php? option=com_content\&view=category\&id=38\&ltemid=54.

24. Escobar Ohmstede A: Historia de los Pueblos Indígenas de México: De la Costa a la Sierra, Las Huastecas. México: CIESAS-INI; 1998:1750-1900.

25. Sandstrom AR: The image of disease: medical practices of Nahua Indians of the Huasteca. In University of Missouri Monographs in Anthropology, No. 3. Department of Anthropology. Columbia: University of Missouri-Columbia; 1978.

26. Avendaño Reyes S: El conocimiento de la flora útil: una base para conservar los recursos vegetales. In Problemática Ambiental en el Estado de Veracruz: Los Recursos Vegetales. Edited by Castillo-Campos G, Mejía-Saulés MT. Xalapa, México: Universidad Veracruzana; 1994:59-67.

27. Ariel de Vidas A: La bella durmiente: el norte de Veracruz. Nuevo Mundo: Mundos Nuevos; 2005. http://nuevomundo.revues.org/574.

28. Ruvalcaba Mercado J: Presentación. In Nuevos aportes al conocimiento de la Huasteca. Edited by Ruvalcaba Mercado J. México: CIESAS; 1998:11-26.

29. Thomas E, Vandebroek I, Van Damme P: What works in the field? a comparison of different interviewing methods in ethnobotany with special reference to the use of photographs. Econ Bot 2007, 614:376-384.

30. Quinlan MB: Ethnomedicine and ethnobotany of fright, a Caribbean culture-bound psychiatric syndrome. J Ethnobiol Ethnomed 2010, 6:9.

31. Emerson RM, Fretz Rl, Shaw LL: Writing Ethnographic Fieldnotes. Chicago: University of Chicago Press; 1995.

32. Vázquez-García V: Gender, ethnicity, and economic status in plant management: un- cultivated edible plants among the Nahua and Popolucas of Veracruz, Mexico. Agri Hum Values 2008, 25:65-77.

33. Alarcón AM, Nahuelcheo Y: Pregnancy, delivery, and post partum beliefs among Mapuche women: private conversations. Chungara, Revista de Antropologá Chilena 2008, 40:193-202.

34. Finkler K: Biomedicine globalized and localized: western medical practices in an outpatient clinic of a Mexican hospital. Soc Sci Med 2004 59:2037-2051.

35. Bussmann RW, Glenn A: Medicinal plants used in Northern Peru for reproductive problems and female health. J Ethnobiol Ethnomed 2010, 6:30.

36. Rubel AJ, Hass MR: Ethnomedicine. In Medical anthropology: contemporary theory and method. Revised edition. Edited by Sargent CF, Johnson TM. Westport: Praeger Publishers; 1996:113-130.

37. López Austin A: Cosmovisión y medicina náhuatl. In Estudios sobre botánica y antropología médica. Edited by Viesca Treviño C. Mexico: Instituto Mexicano para el Estudio de las Plantas Medicinales; 1976:13-27.

38. Etkin NL: Ethnopharmacology: the conjunction of medical ethnography and the biology of therapeutic action. In Medical anthropology: contemporary theory and method. Revised edition. Edited by Sargent CF, Johnson TM. Westport: Praeger Publishers; 1996:151-164.

39. Lamxai V, de Boer HJ, Björk L: Traditions and plant use during pregnancy, childbirth and postpartum recovery by the Kry ethnic group in Lao PDR. J Ethnobiol Ethnomed 2011, 7:14. 
40. Maraesa A: A competition over reproductive authority: prenatal risk assessment in southern Belize. In Risk, reproduction, and narratives of experience. Edited by Fordyce L, Maraesa A. Nashville: Vanderbilt University Press; 2012.

41. Chapman R: Chikotsa-secrets, silence, and hiding: social risk and reproductive vulnerability in central Mozambique. Med Anth Quar 2006, 20:487-515.

42. Manderson L: Shaping reproduction: maternity in early twentieth century Malaya. In Maternities and modernities: colonial and postcolonial experiences in Asia and the Pacific. Edited by Ram K, Jolly M. Cambridge: Cambridge University Press; 1998:26-50.

43. Blanchard K, Elul B, RamaRao S: Reproductive Health Indicators: Moving Forward. New York: Population Council; 1999.

\section{Submit your next manuscript to BioMed Central and take full advantage of:}

- Convenient online submission

- Thorough peer review

- No space constraints or color figure charges

- Immediate publication on acceptance

- Inclusion in PubMed, CAS, Scopus and Google Scholar

- Research which is freely available for redistribution 